Maria Koschig*, Ines Conrad and Steffi G. Riedel-Heller

\title{
Experiences and attitudes towards mental health problems in first year German university students
}

https://doi.org/10.1515/ijamh-2021-0026

Received February 23, 2021; accepted April 18, 2021;

published online May 21, 2021

\section{Abstract}

Objectives: The study should show how familiar German first year university students are with mental health issues and what their attitudes are regarding mental illness.

Methods: The study sample consisted of 293 first year German university students (20.37 years \pm 1.88 ), most of them women $(82.9 \%)$. The majority $(77.6 \%)$ was studying a social type subject. An additive focus group consisted of four experts. The participants of the quantitative part were recruited at prevention workshops that were offered during the induction week at the beginning of the semester at 15 German universities. Experts of the focus group were recruited by telephone call. In addition to quantitative analysis, we realized a focus group with experts of our target group concerns and university system. For statistical analysis, we used statistic software programme "SPSS" 24 to conduct t-tests. We used content-analytical evaluation to build a category system.

Results: Every fourth participant reported having had a mental health problem. Male participants had a slightly greater desire for social distance $(\mathrm{p}=0.008 ; \mathrm{df}=288)$ and slightly stronger stereotypes $(\mathrm{p}<0.001 ; \mathrm{df}=289)$.

Conclusions: The present study shows that first year university students in Germany have substantial experience with mental health problems.

*Corresponding author: Maria Koschig, Institute of Social Medicine, Occupational Health and Public Health, University of Leipzig, PhilippRosenthal-Straße 55, 04103 Leipzig, Germany, Phone: +493419715477, Fax: +493419715409, E-mail: maria.koschig@medizin.uni-leipzig.de Ines Conrad and Steffi G. Riedel-Heller, Institute of Social Medicine, Occupational Health and Public Health, University of Leipzig, Leipzig, Germany, E-mail: ines.conrad@medizin.uni-leipzig.de (I. Conrad), steffi.riedel-heller@medizin.uni-leipzig.de (S.G. Riedel-Heller)
Keywords: adolescence; college issues; discrimination/ stereotypes (bias, prejudice); gender; mental health/ psychopathology.

\section{Introduction}

Late adolescence and early adulthood is an important developmental phase. First, career decisions are made, including the decision to study at a university. First year university students, in particular, are confronted with a number of unique challenges. They have to manage new situations on their own for the first time in their lives. Leaving home, finding new friends, living with roommates, and living independently in an apartment present real challenges for students [1]. In addition, they face new academic demands requiring self-directed study and must adjust to different academic assessment methods.

Most mental disorders start in adolescence and early adulthood [2]. It has been shown that students and especially in the first year are particularly vulnerable. Studies from several countries have shown, that mental health problems are common in college freshmen [3-5]. However, there have been no reports on German first year university students so far. It has been shown that mental health problems negatively affect academic functioning over the subsequent years [4, 6]. Furthermore, a reduction in helpseeking behavior has been reported [7-9]. Several authors have highlighted that stigmatizing attitudes are a barrier to help-seeking behavior in students [7-9].

Therefore, university students in their first year appear to be a special target group for efforts regarding interventions to promote prevention and help-seeking in those affected. According to a German health insurance company report, university students $(6.44 \%)$ were more likely to be diagnosed with depression according to ICD-10 criteria than persons of the same age who were not studying at a university (5.79\%). In addition, a greater use of antidepressants in students was found [10]. These data underpin the need for research in German students, their experiences with mental 
health problems and their attitudes toward mental illness and help-seeking behavior.

\section{Objectives of the study}

This paper seeks to answer following questions:

(1) How familiar are German first year university students with mental health issues? How many German first year university students experienced mental health problems and core-depression symptoms over a two week period ever in their live times? Are there any differences regarding gender or subject studied? (quantitative)

(2) What attitudes do German first year university students hold regarding mental illness in terms of stereotypes, stigmatization and the desire for social distance? Are there any differences in attitudes regarding gender or subject studied? (quantitative)

(3) What is the "Status quo" of mental health culture at German university (practice example)? (qualitative)

\section{Method}

\section{Study design}

The study follows a mixed-method-approach. A quantitative analysis based on questionnaires had been complemented by focus group interviews with experts. It is a cross sectional study.

\section{Study population}

A total of 643 persons filled out the questionnaire, 327 were first year students. For quantitative analysis we were able to include 293 students in their first year of studies (freshmen) with valid data in the final analytic sample. The final sample consisted of 293 German college freshmen with a mean age of 20.37 years $(+1.88)$, most of them women (82.9\%). The majority $(77.6 \%)$ of the sample was studying a social type subject. The response rate was $82 \%$.

For qualitative analysis, we built a focus group with four experts. All of them worked at university at the time of the focus group discussion. They had to do with mental health concerns, worries and mental crisis of students in different areas: central advisory office of the University, psychosocial counseling center of the "Studentenwerk" (the "Studentenwerk" is a service provider for students with a social mission for food, housing, financing, culture etc.), psychosocial counseling center of the Student Council ("StuRa") and psychological counseling center.

\section{Study area}

The quantitative part took place at a workshop for study beginners. The workshop named "Studying and staying mentally healthy" is a universal preventive program that informs young students about mental crisis and mental well-being. Other aspects are help seeking behavior and low-threshold offerings at university. In consequence, we contacted experts at the university who offer these help for students to discuss their use and experiences in the last years.

\section{Study period}

The study started in October 2017 and ended in December 2018.

\section{Sampling method}

The participants of the quantitative part were recruited in 2017 and 2018 at workshops named, "Studying and Staying Mentally Healthy" that were offered during the induction week at the beginning of the semester at 15 German universities. Students were asked to fill out a questionnaire when entering the workshop room.

The experts for mental problems of students were contacted per telephone after a short search of addresses. We invited them for a focus group after the quantitative analysis was final.

\section{Sample size calculation}

We did not calculated a sample size because inferential statistic was not the priority of the study.

\section{Instruments}

A questionnaire was developed to collect sociodemographic information including age, gender, area of study, number of semesters, previous study experiences and self-reported information on mental health issues. In order to evaluate a prior mental health problem, students were asked if they have ever suffered from two core symptoms of depression (a lack of interest and sadness) for a minimum of two weeks ever in their lifetime ("Did you ever have in your life a minimum two-weekphase of reduced interest and joy on more than half of the days?"; "Did you ever have in your life a minimum two-week-phase of sadness on more than half of the days?"). This brief assessment may indicate a past depressive episode. In addition, there were three items which measured how familiar German first year university students are with mental disorders ("Do you know someone with mental illness?" - yes/no; "Have you read or heard something about mental illness?" - yes/no; "Have you had your own experiences with mental health problems?” - yes, repeatedly recurring/yes, infrequently/yes, once/no, but I'm afraid that I might have a problem/no).

Attitudes toward mental illness in terms of stigmatization, stereotypes and a desire for social distance were measured by the Social Distance Scale [11] adapted by Paulus and colleagues [12]. The participants were asked to rate their agreement regarding given statements on a Likert scale 1-5; from "strongly disagree" to "strongly agree". There are three subscales: social distance (10 items), stigmatization (five items), and stereotypes (five items).

Single items developed by researchers were not validated separately. These items are not part of the statistical analyses. For the focus group, we used a semi-structured interview guide. All participants were asked to fill out an informed consent. The discussion was recorded. 


\section{Analysis}

The questionnaire was mainly descriptively analyzed. Item values (range 1-5) as well as calculated sum scores of each attitude subscale were used to analyze the sample. Similar to the procedure used by Kroenke and colleagues [13], we computed a sum score for mental problems in lifetime (range: 0-6 points) and used the cut-off value of three to split the group into students with past mental health problems and students without (or few) past experience with mental health problems. To classify participants area of study, we followed Destatis' categorization of study subjects [14]. In addition we split the sample into area of study and classified first year students as either "social type" subject (like social work, sociology, psychology) or "no social type" subject (like informatics, medicine, politics) to test group differences. t-tests were computed to analyze group differences in social distance mean scores regarding gender and subject. We used SPSS 24 for statistics.

Using the record version of the focus group, we wrote a protocol for qualitative content analysis.

\section{Ethical statement}

Ethical approval was obtained. The ethic committee of University of Leipzig (medical faculty; address: Käthe-Kollwitz-Str. 82, 04109 Leipzig, Germany) gave a positive ethic vote at 14/11/2017, number 424/17-ek.

\section{Results}

\section{Familiarity with mental illness and experiences with self-defined mental health problem}

The majority $(88.6 \%)$ of participants knew someone with a mental illness and $96.6 \%$ had read or heard something about it. Almost two-thirds (63.7\%) of those questioned stated that they have had their own experiences with mental health problems, with $23.6 \%$ reporting a recurring problem. Every third first year student (33.3\%) reported having had a minimum two-week-phase of reduced interest and joy on more than half of the days. In addition, every third participant $(32.7 \%)$ has had a two-week-phase of sadness on more than half of the days in the past. The analysis of the sum score shows, that approximately onefourth $(26.1 \%)$ of our sample has had a minimum two-weekphase of exhibited indicators of depression in the past.

\section{Attitudes toward mental illness}

Overall, the German first year university students in our sample had a low desire for social distance and expressed attitudes that did not reflect negative stereotypes and stigmatization of mentally ill people. The subscale "social distance" had a scale mean of 1.41 indicating an extremely low desire to distance people with mental health problems. Similarly, the "stereotype" subscale had a mean score of 1.65 reflecting an extremely low endorsement of stereotypical beliefs. Interestingly, the stigmatization subscale mean score was moderate at 2.92.

Single item analysis revealed that the social distance subscale item, "I would be embarrassed or ashamed if my friends knew that someone in my family was mentally ill" had higher levels (Tables 1-3). For the stigmatization subscale, the item, "Most adults have a prejudice against someone with mental illness" was the strongest $(M=3.58)$. For the stereotype subscale, respondents agreed most strongly with the item, "Someone who has had mental illness cannot be good at university" $(M=1.92)$.

A two-tailed t-test showed significant $(\mathrm{p}<0.05)$ gender differences in two subscales. The male students had a slight but significant greater desire for social distance $(M$ male=1.59; $M$ female=1.38; $\mathrm{p}=0.008 ; \mathrm{df}=288$ ) and slightly stronger stereotypes $(M$ male $=1.91 ; M$ female=1.60; $\mathrm{p}<0.001 ; \mathrm{df}=289$ ) (Figure 1). We found no gender specific differences in the stigmatization subscale. Overall, the men as well as the women in our sample had low social distance values.

Next to gender specific differences, we analyzed subject type differences. Tables 1-3 show the item means of students studying a social subject and those studying a non-social subject. There are no significant subscale differences. Single item analysis shows significant differences in all performance-related items. First year students beginning study of a social subject have a slightly more negative attitude about the performance of a mentally ill person than students beginning a non-social subject.

\section{Mental health university culture - case example}

Using the content analysis, we conducted a category system (Fig Appendix 1). The participants reported that there are more students asking for help and more users of metal health services. There are internal offers for students with regard to mental health themes but they are unsystematic and the University hasn't a clear health goal. The university in the case example of the present study has its own institutions (f.e. student services, "Studentenwerk") to realize mental health goals but there are only a few external partners. Additionally, internal offers are not sufficient to meet 
Table 1: Social distance subscale "Social distance" with scale statistics (value range 1-5). Values are item means with SD in parentheses, gender specific item means and subject specific items means.

\begin{tabular}{|c|c|c|c|c|c|c|c|}
\hline \multicolumn{2}{|l|}{ Subscale: social distance } & \multicolumn{3}{|c|}{ Gender specific } & \multicolumn{3}{|c|}{ Subject specific } \\
\hline Scale mean: $1.41 \pm 0.39(n=291)$ & Item mean, SD & Female, $\boldsymbol{M}$ & Male, $M$ & p-Value & Non-social, $M$ & Social, $\boldsymbol{M}$ & p-Value \\
\hline $\begin{array}{l}\text { I would be afraid to talk to someone who is } \\
\text { mentally ill. }\end{array}$ & $1.32(0.61)$ & 1.31 & 1.40 & 0.34 & 1.37 & 1.30 & 0.43 \\
\hline $\begin{array}{l}\text { I could imagine making friends with someone who is } \\
\text { mentally ill. }\end{array}$ & $4.63(0.73)$ & 4.64 & 4.56 & 0.49 & 4.66 & 4.63 & 0.72 \\
\hline $\begin{array}{l}\text { I would be embarrassed or ashamed if my friends knew } \\
\text { that someone in my family was mentally ill. }\end{array}$ & $2.00(1.03)$ & 2.00 & 2.02 & 0.90 & 2.02 & 2.00 & 0.89 \\
\hline $\begin{array}{l}\text { If the person sitting next to me in class developed } \\
\text { mental illness, I would rather sit somewhere else. }\end{array}$ & $1.23(0.58)$ & 1.17 & 1.56 & 0.00 * & 1.23 & 1.23 & 0.99 \\
\hline $\begin{array}{l}\text { If one of my friends developed mental illness, } \\
\text { I would go and see him/her at the hospital. }\end{array}$ & $4.85(0.47)$ & 4.88 & 4.65 & $0.01^{*}$ & 4.91 & 4.83 & 0.08 \\
\hline $\begin{array}{l}\text { I would not invite someone who has had mental illness } \\
\text { to my party. }\end{array}$ & $1.35(0.71)$ & 1.29 & 1.64 & $0.02 *$ & 1.45 & 1.32 & 0.13 \\
\hline $\begin{array}{l}\text { I would not bring along someone who is mentally ill when } \\
\text { I meet my friends. }\end{array}$ & $1.42(0.81)$ & 1.34 & 1.80 & $0.00 *$ & 1.40 & 1.40 & 0.97 \\
\hline $\begin{array}{l}\text { When going on a class outing, someone who is mentally } \\
\text { ill should rather stay at home. }\end{array}$ & $1.30(0.64)$ & 1.28 & 1.43 & 0.25 & 1.15 & 1.34 & $0.01^{*}$ \\
\hline $\begin{array}{l}\text { I would never fall in love with someone who is } \\
\text { mentally ill. }\end{array}$ & $1.52(0.81)$ & 1.48 & 1.71 & 0.07 & 1.39 & 1.54 & 0.18 \\
\hline $\begin{array}{l}\text { Someone who is mentally ill should not work in jobs } \\
\text { that involve taking care of children or young people. }\end{array}$ & $1.76(0.83)$ & 1.74 & 1.86 & 0.37 & 1.55 & 1.83 & $0.02 *$ \\
\hline Someone who is mentally ill should not go to university. & $1.15(0.49)$ & 1.13 & 1.28 & 0.21 & 1.03 & 1.19 & 0.00 * \\
\hline
\end{tabular}

*Significant $p$-Values $(p<0.05)$ are highlighted in bold.

Table 2: Social distance subscale "Stigmatization" with scale statistics (value range 1-5). Values are item means with SD in parentheses, gender specific item means and subject specific items means.

\begin{tabular}{|c|c|c|c|c|c|c|c|}
\hline \multicolumn{2}{|l|}{ Subscale: stigmatization } & \multicolumn{3}{|c|}{ Gender specific } & \multicolumn{3}{|c|}{ Subject specific } \\
\hline Scale mean: $2.92 \pm 0.58(n=289)$ & Item mean, SD & Female, $\boldsymbol{M}$ & Male, $M$ & p-Value & Non-social, $M$ & Social, $M$ & p-Value \\
\hline $\begin{array}{l}\text { Most adults have a prejudice against someone } \\
\text { with mentally illness. }\end{array}$ & $3.55(0.89)$ & 3.54 & 3.55 & 0.96 & 3.64 & 3.52 & 0.33 \\
\hline $\begin{array}{l}\text { Most young people have a prejudice against } \\
\text { someone with mentally illness. }\end{array}$ & $3.52(0.89)$ & 3.51 & 3.58 & 0.62 & 3.64 & 3.49 & 0.23 \\
\hline $\begin{array}{l}\text { Most people don't have a problem being friends with } \\
\text { someone who is mentally ill. }\end{array}$ & $3.41(0.87)$ & 3.42 & 3.36 & 0.64 & 3.41 & 3.41 & 0.95 \\
\hline $\begin{array}{l}\text { Someone with mental illness can find a partner just } \\
\text { as well as other people. }\end{array}$ & $3.50(0.99)$ & 3.62 & 2.94 & $0.00 *$ & 3.51 & 3.50 & 0.97 \\
\hline $\begin{array}{l}\text { Someone with mental illness has problems with } \\
\text { finding an apprenticeship/study/work place. }\end{array}$ & $2.47(1.08)$ & 2.43 & 2.70 & 0.10 & 2.37 & 2.51 & $0.00 *$ \\
\hline
\end{tabular}

*Significant $p$-Values $(p<0.05)$ are highlighted in bold.

the needs of the students; further steps need to be taken (compare Fig Appendix 1).

Discussed barriers to the development of a mental health university center are f.e.: no health goal, inflexible structures, lack of support from university management, lack of knowledge (university staff), lack of money and lack of motivation to learn something about "Healthy University". Beneficial factors for a "mentally healthy university" are f.e. regular offers, development of new structures, networking, service presenting, good reachability, clear information for students and university staff and initiative of external partners. 
Table 3: Social distance subscale "Stereotypes" with scale statistics (value range 1-5). Values are item means with SD in parentheses, gender specific item means and subject specific items means.

\begin{tabular}{|c|c|c|c|c|c|c|c|}
\hline \multicolumn{2}{|l|}{ Subscale: stereotypes } & \multicolumn{3}{|c|}{ Gender specific } & \multicolumn{3}{|c|}{ Subject specific } \\
\hline Scale mean: $1.65 \pm 0.47(n=292)$ & Item mean, SD & Female, $\boldsymbol{M}$ & Male, $M$ & p-Value & Non-social, $M$ & Social, $\boldsymbol{M}$ & p-Value \\
\hline $\begin{array}{l}\text { Someone who has had mental illness has } \\
\text { to blame her/himself. }\end{array}$ & $1.43(0.73)$ & 1.35 & 1.82 & $0.00 *$ & 1.29 & 1.48 & $0.04^{*}$ \\
\hline $\begin{array}{l}\text { Someone who has had mental illness cannot } \\
\text { be helped by doctors. }\end{array}$ & $1.49(0.77)$ & 1.43 & 1.74 & 0.06 & 1.45 & 1.50 & 0.62 \\
\hline $\begin{array}{l}\text { Someone who has had mental illness overreacts } \\
\text { to small matters. }\end{array}$ & $1.70(0.86)$ & 1.67 & 1.88 & 0.11 & 1.71 & 1.71 & 0.99 \\
\hline $\begin{array}{l}\text { Someone who has had mental illness poses } \\
\text { a threat to other people. }\end{array}$ & $1.69(0.79)$ & 1.65 & 1.88 & 0.06 & 1.63 & 1.70 & 0.52 \\
\hline $\begin{array}{l}\text { Someone who has had mental illness cannot } \\
\text { be good at university. }\end{array}$ & $1.94(1.21)$ & 1.88 & 2.22 & 0.11 & 1.51 & 2.07 & $0.00^{*}$ \\
\hline
\end{tabular}

*Significant $p$-Values $(p<0.05)$ are highlighted in bold.

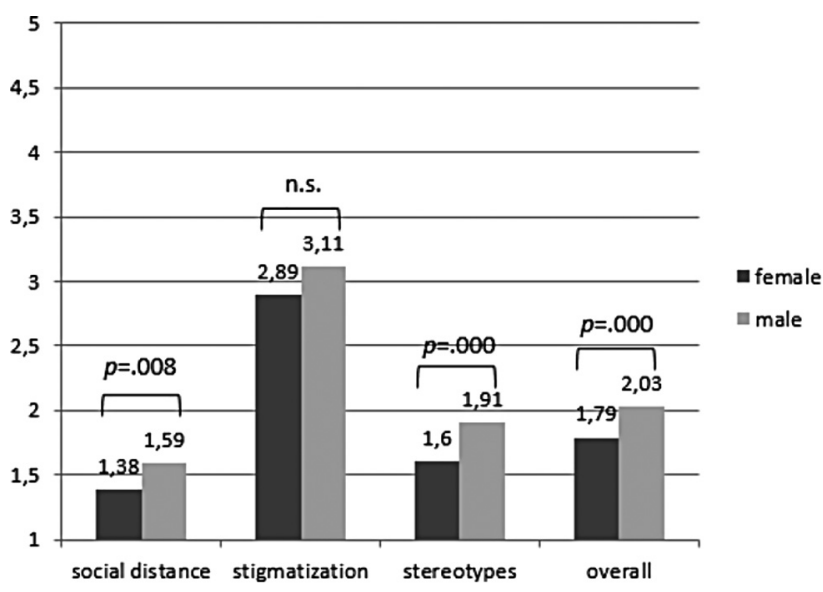

Figure 1: Gender specific differences for the three subscales and global social distance scale (value range 1-5).

The four experts talked about existing preventive offers at the case example with regard to mental health and mental crisis. The inclusion plan of the University gives advice about psychological counseling offers. The workshop "long night of procrastinated works" try to offer information about pressure, stress and test anxiety. A general mentoring program shall help students with worries and uncertainties. Additionally, there is a great variety of sports classes for students.

\section{Discussion}

The aim of the study was to evaluate past experiences with mental health problems in German first year university students and to examine their attitudes around that topic. Additionally, the interview of experts should generate a structural perspective around the topic "Mental health concerns at German university".

It is known that beginning higher education is a potentially high stressful time. Moreover, it is the period of life when most mental diseases occur for the first time. It is necessary to understand the associated concerns and problems of the target group to develop an adequate preventive program.

\section{How much experience did German first year university students have with mental health problems?}

Almost every participant in the sample had already had some contact with the topic either because of a friend with mental health problems or their own experiences. Every third student reported having had a minimum two-weekphase of emotional difficulty in past. The present results for German first year university students can be compared with data on American college students between age 18 and 24 [15]. 34.5\% of the American college students reported that they felt so depressed during the last 12 months that it was difficult to function. The German findings are also comparable with a representative Belgian sample of 4,921 first year university students [4]. Every third Belgian first year student (34.9\%) reported a mental health problem in the past year. However, different instruments were used to assess mental health. In contrast, the rate of depressive and anxiety symptoms in a Chinese sample was considerably higher than the measured and reported rates of the Western industrial states [16]. A Mexican study measured depressive 
symptoms in 1,122 students (mean age $=20 \pm 1.98$ ). Depressive symptoms were observed in $20.4 \%$ of the students (24.2\% women and $15.7 \%$ men, $\mathrm{p}<0.01$ ) [17].

\section{How strong are stereotypes, stigmatization and the desire for greater social distance?}

Overall, the desire for social distance towards mentally ill people was low in our sample compared to the general population attitudes towards persons with depression or eating disorders $[18,19]$. Unfortunately, there are no comparable data from other first year students. However, we can compare our findings with social distance data on children in a school-based mental fitness project [20]. The children (range: $12-16$ years) had quite similar low levels of stigmatization, stereotypes and social distance.

On social distance subscale, the item with the highest agreement in our sample was: "I would be embarrassed or ashamed if my friends knew that someone in my family was mentally ill." In comparison with other findings, it is striking to see that statements with personal involvement provoke the highest social distance scores. For instance, Dyrbye and colleagues [7] investigated 873 medical students. They measured the highest agreement to the item, "If I were to receive treatment for an emotional/ mental health problem, I would hide it from people." In this case, $47.8 \%$ of respondents agreed and $14.1 \%$ of respondents strongly agreed with this item, reflecting a form of self-stigmatization.

On subscale stigmatization the items: "Most adults have a prejudice against someone with mentally illness." and "Most people don't have a problem being friends with someone who is mentally ill." (inverted item) had highest agreement. Moreover, the majority of our sample disagreed with all stereotypical statements, so there is a relatively low level of stereotyping. The only performance-based item ("Someone who has had mentally illness cannot be good at university.") had a little higher agreement level with an item mean of 1.92. These results are similar to those of Dyrbye and colleagues [7]. More than 50\% of the medical students from the Dyrbye sample agreed with the performance-based item, "My supervisors (e.g., faculty, residents, deans) would see me in a less favorable way if they believed that I had an emotional/mental health problem." In conclusion, performance beliefs seem to be associated with mental health stigmatizations in university students.

\section{Are there any group effects regarding gender and study subject?}

Our analysis showed that the male students in our sample had significantly higher social distance scores for stereotypes and social distance subscales and global score, as seen in Figure 1. A similar gender effect was reported by Corrieri and colleagues $[20,21]$ in a school-based mental fitness coaching project. They measured social distance with the same questionnaire [11]. Participants consisted of 592 students (range: $12-16$ years). Boys had a higher social distance than girls. The researchers also reported a "type of school" effect, indicating that higher educated students had lower social distance scores. These findings fit to the relatively low social distance scores in the present study of a sample with higheducated participants.

Subject differences with regards to stereotypes, stigmatization and social distance occur only for performancerelated items. Students studying a social welfare subject more often expect poor performance and problems at university than the other first year students. It could be hypothesized that they might be more sensitized to the topic. However, there are no data on this in other studies.

\section{Status quo - "The Mentally Healthy German University”}

The focus group discussion showed some barriers for the development of university culture with mental health goals. The lack of an overall mental health goal seemed to be most important. Other barriers were lack of knowledge, lack of motivation (of university staff) to inform about mental health, inflexible structures at the university, lack of support from university management.

A short look at the literature showed effective programs and emphasized the reported lack of knowledge; f.e.: A meta-analysis of randomized controlled trials showed that cognitive-behavioral and mindfulness-based prevention programs are effective in reducing depression and anxiety symptoms in university students [22]. Another meta-analysis of internet interventions for mental health in university students found low effects in reducing depression, anxiety and stress; and moderate effects in reducing eating disorder symptoms [23].

Gulliver and colleagues [24] investigated staff experiences of students with mental health problems and their perceptions of staff training needs. This survey- 
based study found similar barriers like reported from the focus group members of the present study: Between 70 and $83 \%$ of the university staff reported moderate confidence in their ability to provide emotional help for students. More than the half (60\%) felt under-equipped to handle mental crisis of their students and almost the half had no possibility for formal training. The last point indeed structural problems at the university, which focus group members reported, too.

\section{Limitations}

The study did not have a randomized design because data collection was conducted via participation in the program "Studying and Staying Mentally Healthy" under real life conditions. The program was open to all students at almost all joining universities. The program was mainly designed for students in their first semester. It might be reasonably assumed that students joined the session were particularly interested in the theme. This may have led to a selection bias. With $75.5 \%$ studying a social type subject, these students were over represented in our sample.

\section{Conclusion \& future research}

All together, the present study showed that first year German university students have had considerable experiences with mental health problems. The rates of sadness and reduced interest are comparable to other first year students in Western industrial states. There is a gender effect towards social distance, stereotypes and stigmatization with regards to mental illness for German university students in their first year. Stigmatizations occurred at low levels.

How can we protect students from becoming mentally ill or manifesting a mental illness? Serious mental health problems in college students are associated with lower academic performance and reduced help-seeking behavior $[3,6-9]$. The idea is to reduce barriers, like stigmatization, to mental health treatment in order to improve access to care and ultimately to improve the mental health of college students. Telles-Correia and colleagues [25] intervened with medical students with mental illness problems and significantly reversed negative and dysfunctional attitudes towards mental health. Fernandez and colleagues [26] published a meta-analysis of interventions to promote mental health at universities. They showed that the most successful programs were courses included in curricula with more sessions and practical help e.g. using new media. A study by Conley and colleagues [27] highlighted the role of supervised practice components. Cognitive behavioral and mindfulness-based approaches are most effective for depression and anxiety [22]. The university can take a leading role in the development of student mental health care [28].

\section{Recommendation}

A relevant part of young students who started at university had or have own experience with metal crisis. From literature, we know that they are in a sensible transition phase. Mental problems at this time have the potential to manifest in adulthood. Therefore, it is necessary to implement lowthreshold offerings at university.

\section{Highlights}

Every fourth young student reported having had a mental health problem.

There is a lack of an overall mental health goal at university.

Low-threshold offerings at university are necessary.

Networking between offerings and external centers can be a beneficial factor in developing mentally healthy university strategies.

Acknowledgments: We thank all students for their participation, the "Irrsinnig Menschlich" society for the collaboration, the proofreader and the reviewers for commenting this manuscript.

Research funding: This work was supported by the BARMER Gesundheitskasse.

Author contributions: All authors have accepted responsibility for the entire content of this manuscript and approved its submission.

Competing interests: Authors state no conflict of interest. Informed consent: Informed consent was obtained from all individuals included in this study.

Ethical approval: The local Institutional Review Board deemed the study exempt from review. 


\section{Appendix}

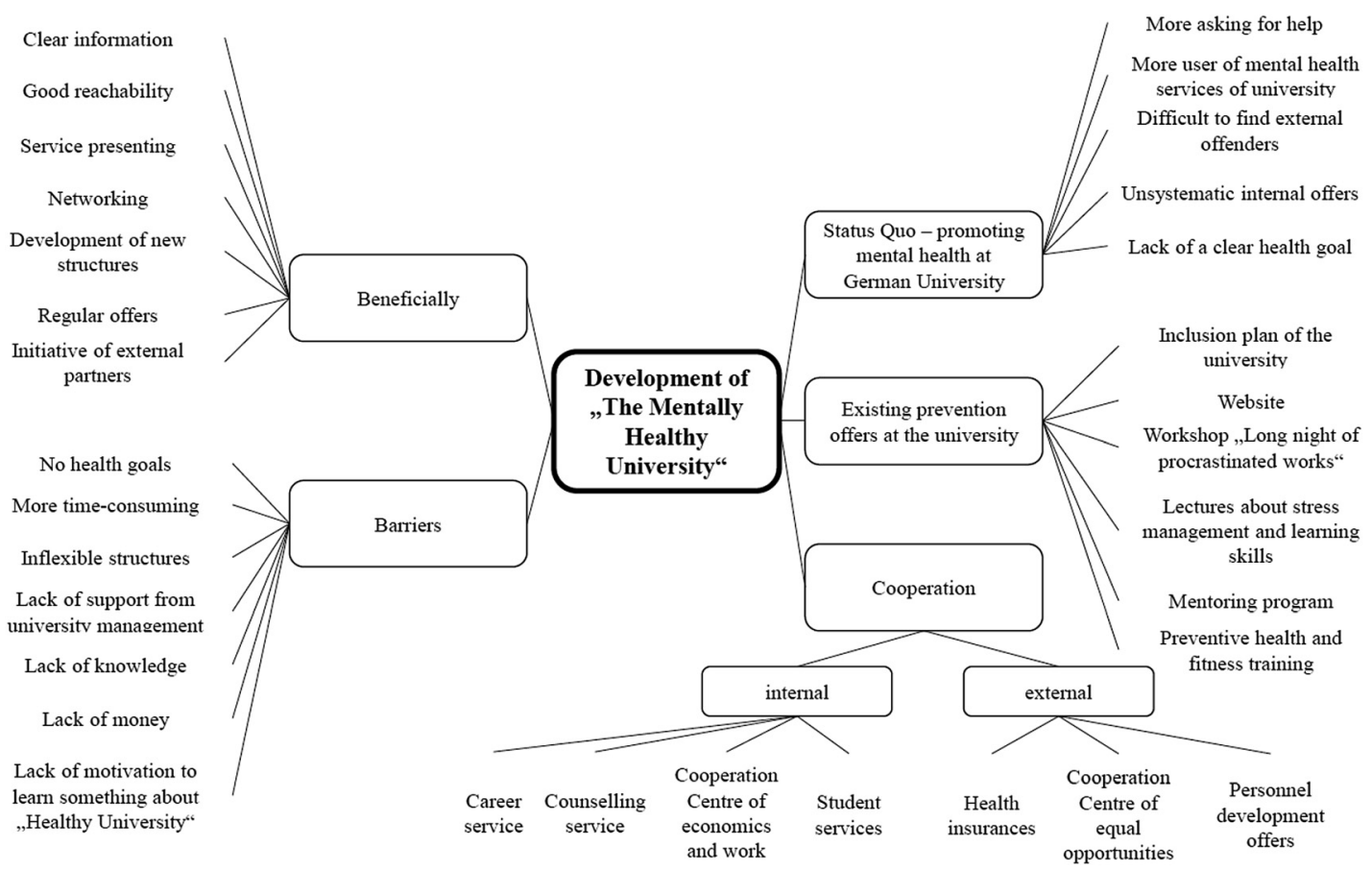

Appendix 1: Category system of the focus group discussion.

\section{References}

1. Ruberman L. Challenges in the transition to college: the perspective of the therapist back home. Am J Psychother 2014;68: 103-15.

2. Silva SA, Silva SU, Ronca DB, Gonçalves VSS, Dutra ES, Carvalho KMB. Common mental disorders prevalence in adolescents: a systematic review and meta-analyses. PloS One 2020;15:e0232007.

3. Barbosa J, Silva Á, Ferreira MA, Severo M. Transition from secondary school to medical school: the role of self-study and selfregulated learning skills in freshman burnout. Acta Med Port 2016; 29:803-8.

4. Bruffaerts R, Mortier P, Kiekens G, Auerbach RP, Cuijpers P, Demyttenaere $\mathrm{K}$ et al. Mental health problems in college freshmen: prevalence and academic functioning. J Affect Disord 2018;225: 97-103.

5. Jamshidi F, Mogehi S, Cheraghi M, Jafari SF, Kabi I, Rashidi L. A cross-sectional study of psychiatric disorders in medical sciences students. Mater Sociomed 2017;29:188-91.

6. Baumann M, Amara M-E, Karavdic S, Limbach-Reich A. First-year at university: the effect of academic employability skills and physical quality of life on students' well-being. Work 2014;49:505-15.

7. Dyrbye LN, Eacker A, Durning SJ, Brazeau C, Moutier C, Massie FS et al. The impact of stigma and personal experiences on the helpseeking behaviors of medical students with burnout. Acad Med 2015;90:961-9.
8. Bohon LM, Cotter KA, Kravitz RL, Cello PC, Fernandez Y, Garcia E. The theory of planned behavior as it predicts potential intention to seek mental health services for depression among college students. J Am Coll Health 2016;64:593-603.

9. Wimsatt LA, Schwenk TL, Sen A. Predictors of depression stigma in medical students: potential targets for prevention and education. Am J Prev Med 2015;49:703-14.

10. Techniker Krankenkasse TK. Gesundheitsreport 2015: Gesundheit von Studierenden; 2015. Available from: www.tk.de.

11. Schulze B, Richter-Werling $M$, Matschinger $\mathrm{H}$, Angermeyer MC. Crazy? So what! Effects of a school project on students' attitudes towards people with schizophrenia. Acta Psychiatr Scand 2003; 107:142-50.

12. Conrad I, Dietrich S, Heider D, Blume A, Angermeyer MC, RiedelHeller S. Crazy?: so what! Health Educ 2009;109:314-28.

13. Kroenke K, Spitzer RL, Williams JBW. The Patient Health Questionnaire-2: validity of a two-item depression screener. Med Care 2003;41:1284-92.

14. Destatis. Statistisches Bundesamt. Bildung und Kultur. Studierende an Hochschulen: Fächersystematik; 2018. Available from: https:// www.destatis.de/DE/Methoden/Klassifikationen/BildungKultur/ StudentenPruefungsstatistik.pdf?_blob=publicationFile.

15. American College Health Association. American College Health Association-National College Health Assessment II: Reference Group Executive Summary Spring 2015; 2015. Available from: http://www.acha-ncha.org/docs/NCHA-II_WEB_SPRING_2015_ REFERENCE_GROUP_EXECUTIVE_SUMMARY.pdf. 
16. Lu W, Bian Q, Song Y, Ren J, Xu X, Zhao M. Prevalence and related risk factors of anxiety and depression among Chinese college freshmen. J Huazhong Univ Sci Technol - Med Sci 2015;35: 815-22.

17. Lazarevich, I, Irigoyen-Camacho, ME, Velázquez-Alva Mdel, C Obesity, eating behaviour and mental health among university students in Mexico City. Nutr Hosp 2013:1892-9. https://doi. org/10.3305/nutr hosp.v28in06.6873.

18. von dem Knesebeck O, Mnich E, Kofahl C, Makowski AC, Lambert M, Karow A et al. Estimated prevalence of mental disorders and the desire for social distance - results from population surveys in two large German cities. Psychiatr Res 2013;209:670-4.

19. von dem Knesebeck O, Angermeyer MC, Kofahl C, Makowski AC, Mnich E. Education and the public's desire for social distance from people with depression and schizophrenia: the contribution of emotional reactions and causal attributions. Int J Soc Psychiatr 2014;60:468-73.

20. Corrieri S, Heider D, Conrad I, Riedel-Heller SG. Evaluation des Projekts "Schulcoaches - Seelische Fitness stärken und Selbsthilfe aktivieren". Gesundheitswesen 2011;73. https://doi. org/10.1055/s-0031-1283428.

21. Corrieri S, Conrad I, Riedel-Heller SG. Die Förderung psychischer Gesundheit in der Schule durch Schulcoaches: Evaluation eines Modellprojekts in Sachsen. Psychiatr Prax 2015;42:82-9.
22. Huang J, Nigatu YT, Smail-Crevier R, Zhang X, Wang J. Interventions for common mental health problems among university and college students: a systematic review and metaanalysis of randomized controlled trials. J Psychiatr Res 2018; 107:1-10.

23. Harrer M, Adam SH, Baumeister H, Cuijpers P, Karyotaki E, Auerbach RP et al. Internet interventions for mental health in university students: a systematic review and meta-analysis. Int J Methods Psychiatr Res 2019;28:e1759.

24. Gulliver A, Farrer L, Bennett K, Ali K, Hellsing A, Katruss $\mathrm{N}$ et al. University staff experiences of students with mental health problems and their perceptions of staff training needs. J Ment Health 2018;27:247-56.

25. Telles-Correia D, Gama Marques J, Gramaça J, Sampaio D. Stigma and attitudes towards psychiatric patients in Portuguese medical students. Acta Med Port 2015;28:715-9.

26. Fernandez A, Howse E, Rubio-Valera M, Thorncraft K, Noone J, Luu $X$ et al. Setting-based interventions to promote mental health at the university: a systematic review. Int J Publ Health 2016;61: 797-807.

27. Conley CS, Durlak JA, Kirsch AC. A meta-analysis of universal mental health prevention programs for higher education students. Prev Sci 2015;16:487-507.

28. Duffy A, Saunders KEA, Malhi GS, Patten S, Cipriani A, McNevin SH et al. Mental health care for university students: a way forward? Lancet Psychiatry 2019;6:885-7. 